\title{
FORMAÇÃO DE PROFESSORES NO BRASIL: POLÍTICAS E PROGRAMAS
}

\author{
Bernardete A. Gatti \\ gattibe@gmail.com \\ https://orcid.org/0000-0002-9297-726X \\ Fundação Carlos Chagas (FCC) \\ São Paulo - Brasil
}

Recibido: 18/01/2021 Aceptado: 25/02/2021

\begin{abstract}
Resumo
Neste artigo são discutidas as políticas e os programas nacionais propostos para a formação de professores para a Educação Básica no Brasil, principalmente nas duas últimas décadas. Entrados nos anos 2000 variadas iniciativas tiveram curso originadas por políticas governamentais, apoiadas por Leis do Congresso Nacional, Decretos da Presidência, Pareceres e Resoluções do Conselho Nacional de Educação, Portarias Ministeriais. Esforços políticos foram desenvolvidos na direção de melhor qualificar a formação de professores, porém, como os dados apontam, ainda não demos conta desse desafio, o que é atestado pelas pesquisas que estudam essas políticas e seus efeitos. Duas características principais são apontadas: a descontinuidade nas implementações, ou reformulações sucessivas, e, a fragmentação de ações, com superposições, entre os vários órgãos governamentais. Por outro lado, são trazidas à luz exemplos de iniciativas institucionais localizadas, levadas avante por grupos de docentes da educação superior e gestores que inovam na forma como concebem e realizam a formação para a docência.
\end{abstract}

Palavras-chave: formação de professores, políticas educacionais, gestão de programas; magistério; inovação curricular.

\section{FORMACIÓN DE PROFESORES EN BRASIL: POLÍTICAS Y PROGRAMAS}

\section{Resumen}

Este artículo presenta una discusión de políticas y programas nacionales que fueran propuestos hacia la formación de docentes para la Educación Básica en Brasil en las dos últimas décadas. A partir de los años 2000 muchas iniciativas gubernamentales fueran originadas, soportadas por Leyes, Decretos y Resoluciones del Consejo Nacional de Educación. Esfuerzos políticos se hicieran para mejorar la calidad de las formaciones para el trabajo docente pero las investigaciones muestran que las metas pretendidas no fueran logradas en su totalidad. Dos principales factores son apuntados: la discontinuidad de las políticas o de los programas e la fragmentación de las acciones por diferentes sectores, con superposiciones de propuestas, o sea, ausencia de articulación entre organismos gubernamentales. Por otro lado, se exponen iniciativas institucionales localizadas que muestran innovaciones en sus propuestas para la formación de profesores.

Palabras clave: formación de profesores, políticas educacionales; gestión de programas; magisterio; innovación curricular. 


\title{
TEACHERS EDUCATION IN BRAZIL: POLICIES AND PROGRAMS
}

\begin{abstract}
This article discuss national policies and programs for teachers education developed by brazilian government during the two last decades. Many initiatives were made whitch are translated in Laws, Decrees and orientations of the National Education Council. Political efforts were made to improve teachers education but researches reveals that the results have not been achieved. Discontinuity and fragmentation of actions are pointed as factors that cause these problems. On the other hand, initiatives of some universities which shows innovations on teachers education are exposed as exemple that is possible to change the status quo of teachers education.

Key-words: teacher education; educational policies; program management; teaching; curriculum innovation
\end{abstract}

\section{Introdução}

Tomando os anos mil novecentos e noventa como ponto de partida, no Brasil momento em que se procura instalar um regime democrático - observa-se que várias iniciativas em políticas dirigidas à educação básica e à formação de professores tomaram corpo e se sucederam em vários governos até aqui. Sinalizaremos alguns dos esforços políticos em educação que foram desenvolvidos na direção de melhor qualificar a formação de professores no Brasil, lembrando que ainda não demos conta desse desafio, o que é atestado pelas análises contidas, por exemplo, em parecer do Conselho Nacional de Educação, Parecer CNE/CP 2/2015 (Brasil, 2015a), e, por pesquisas sobre o currículo de licenciaturas. No entanto, há que se sinalizar que nos últimos anos algumas experiências inovadoras, de caráter institucional local, vêm sendo ensaiadas. Trazem um sopro renovador, com novos formatos e tipos de abordagem para essa formação, o que pretendemos tratar mais adiante neste artigo.

\section{Políticas e formação de professores para a Educação Básica}

Marco do período que estamos tratando foi a promulgação da Lei 9394/96 - Lei de Diretrizes e Bases da Educação Nacional (Brasil, 1996) que consolidou a estrutura da educação escolar nacional, definiu responsabilidades e caracterizou cada modalidade e nível dessa educação. Constituiu-se em eixo referencial nos anos subsequentes e até hoje. Até aqui recebeu mais de duzentas reformulações distribuídas em vários artigos, em decorrência de necessidades conjunturais e de novas demandas, algumas de grande importância como a extensão do Ensino Fundamental para nove anos e, mais recentemente, a reformulação do Ensino Médio. Quanto à formação de professores para a Educação Básica trouxe novas propostas que, mesmo ainda 
constando no texto sem alterações, não foram implementadas. Trata-se dos Institutos Superiores de Educação e das Escolas Normais Superiores. Em 2002 o Conselho Nacional de Educação (CNE) formulou Diretrizes Curriculares Nacionais para a Formação de Professores válidas para todas as licenciaturas que deveriam a elas se adequar. Propunha: a coerência entre a formação oferecida e a prática esperada do futuro professor; a pesquisa, com foco no ensino e na aprendizagem, para compreensão do processo de construção do conhecimento; a prática presente desde o início do curso, e, flexibilidade para que cada instituição formadora construísse projetos inovadores com identidade própria. (Brasil, 2002). Poucas licenciaturas de fato se pautaram por essa Resolução do $\mathrm{CNE}$, continuando com a oferta na perspectiva de um bacharelado como mostram pesquisas posteriores. (Gatti, 2015). Justamente pela constatação de problemas continuados na oferta dos cursos de graduação para a formação inicial de professores é que o CNE elabora estudo que está consolidado no Parecer CNE/CP 02/2015 de junho desse ano, que, com suas análises, fundamentou a Resolução CNE/CP 02/2015 (Brasil, 2015 e 2015a), de julho do mesmo ano, propondo novas orientações para os cursos de formação inicial e continuada de professores, revogando a Resolução CNE/CP 01/2002. Em seu capítulo II, a nova Resolução propõe a base curricular comum nacional para a formação de docentes. Essa proposta está apoiada em pressupostos éticos relativos à equidade e respeito à diversidade, estipulando que as licenciaturas devem ter currículo com identidade própria (Art. 11), fundada no domínio dos conhecimentos científicos e didáticos e reconhecendo as instituições de educação básica como espaços necessários à formação dos profissionais do magistério. Sua entrada em vigor foi adiada várias vezes, por interveniência de grupos diversos, até que, com mudanças nas condições políticas ao nível federal, sobreveio uma nova orientação através da Resolução CNE/CP 02/2019 (Brasil, 2019) que traz outras Diretrizes Curriculares Nacionais para a Formação Inicial de Professores para a Educação Básica e institui a Base Nacional Comum para a Formação Inicial de Professores da Educação Básica (BNC-Formação), revogando a Resolução CNE/CP 02/2015. A nova Resolução ainda não entrou em vigor até este momento, em parte devido à emergência da pandemia Covid-19 que levou a alterações no funcionamento geral das instituições educacionais, sobrestando mudanças curriculares de base.

Interessante é notar que, nos últimos sete anos muitos cursos superiores tiveram alterações curriculares implementadas, orientadas por Resoluções do CNE, como os de medicina, direito, engenharias, entre outros, e as propostas para a formação de profissionais para 
o magistério na educação básica foram adiadas. Esta dificuldade com alterações curriculares especialmente para as licenciaturas levanta a questão da dificuldade de consenso mínimo em torno de uma perspectiva formativa para professores da educação básica e questões sobre o real valor dado pelos agentes da educação superior a um curso de graduação com tal vocação, integrado e com características próprias.

\section{Políticas para o magistério e a formação de professores}

Além das tentativas do CNE de induzir mudanças na formação inicial de professores, também formulou proposta sobre Planos de Carreira Docente que visou equacionar a questão de se oferecer uma perspectiva de progressão na profissão docente nas diferentes redes de ensino. (Brasil, 2009).

O Ministério da Educação (MEC) encetou várias políticas visando o cenário complexo e problemático da educação básica, tanto para aumentar a oferta de licenciaturas, como para qualificar a melhor as formações e para a valorização do magistério. Sobre esta última questão atuou decisivamente na aprovação e promulgação da Lei do Piso Salarial Nacional do Magistério (Brasil, 2008) com o objetivo de propiciar a melhoria das condições de remuneração do magistério na educação básica, cujo impacto se esperaria que pudesse ser sentido tanto na atratividade da carreira docente, como nas condições do trabalho docente. Os efeitos desses dispositivos sobre o estímulo e atratividade para a carreira docente, seu aperfeiçoamento e diversificação na progressão profissional ainda não são palpáveis até nossos dias. A diversidade de situações e redes de ensino no Brasil é muito grande, suas condições financeiras também, em que pese o papel redistributivo do Fundeb - Fundo de Manutenção e Desenvolvimento da Educação Básica e de Valorização dos Profissionais da Educação - e o percentual orçamentário nele contido voltado aos docentes. (Brasil, 2006; 2007c). Em boa parte, os dispositivos de carreira e do piso salarial nacional do magistério, ainda não chegam a ser observados em muitos governos, quer estaduais quer municipais. Carreiras e condições de trabalho se mostram com precariedades palpáveis. (Gatti et al., 2019; Jacomini e Penna, 2016; Leite, 2014).

A proposta de criação da Universidade Aberta do Brasil - UAB (Brasil, 2006a) veio trazer condições para a expansão do ensino à distância nos cursos superiores e, com legislações de apoio posteriores a expansão dessa modalidade de ensino para a oferta de licenciaturas, especialmente o curso de Pedagogia, foi muito grande, especialmente nas regiões mais 
populosas e com condições econômicas melhores, considerando que essa expansão se deu especialmente através das instituições de ensino superior privadas. Embora o papel do ensino à distância seja importante, e as normas existentes quanto à oferta de cursos na modalidade $\mathrm{EaD}$ sejam exigentes, estudos têm evidenciado a fragilidade na oferta, nas dinâmicas de aprendizagem e nas avaliações. (Pretto e Lapa, 2010). É constatável que se tem caminhado, nas políticas, na direção de ampliação cada vez maior na oferta de cursos de graduação a distância. Pelo Decreto No $9057 / 2017$ (Brasil, 2017), sem que se tenha feito análise mais acurada da qualidade dos cursos já ofertados, é permitido que as instituições de ensino superior aumentem sua oferta nessa modalidade para graduações sem exigir credenciamento prévio para oferta de cursos presenciais e, elas podem criar seus polos independente de autorização. O Decreto citado se refere a todos os tipos de formação, mas, pelo histórico até aqui, os cursos que são oferecidos em maior número na modalidade EaD, como já dissemos, são as licenciaturas.

\section{Políticas federais abrangentes}

Em 2004 se criou a Rede Nacional de Formação Continuada de Profissionais da Educação Básica (Brasil, 2006) para a oferta de formação em serviço de docentes em exercício nas redes escolares públicas, envolvendo instituições públicas de ensino superior, as comunitárias e sem fins lucrativos, e os institutos federais de educação, ciência e tecnologia, sendo colocado que esse programa deveria definir e coordenar a atuação das diferentes secretarias do MEC, da Capes (Coordenadoria de Aperfeiçoamento de Pessoal do Ensino Superior) e do Fnde (Fundo Nacional de Desenvolvimento da Educação) com as instituições de ensino superior e os sistemas de ensino para o desenvolvimento dessa formação. Ações estratégicas, como o Pró-Letramento e o Gestar II, Especialização em Educação Infantil, entre outras, foram desdobramentos dessa proposta, bem como grande número de oferta no âmbito da consideração das diversidades. Na prática, as diversas ações desencadeadas se constituíram como programas esparsos em vários órgãos, com muitas e variadas propostas, praticamente sem articulação. Analisando esta dispersão tentou-se implementar uma política mais integrada. Pelo Decreto No 6.755/2009 (Brasil, 2009) foi instituída a Política Nacional de Formação de Profissionais do Magistério da Educação Básica que propunha várias ações como a instalação dos Fóruns Estaduais Permanentes de Apoio à Formação Docente; o estímulo à oferta de licenciaturas por parte a UAB - Universidade Aberta do Brasil; o Programa Pró-Licenciatura: formação inicial/complementar, e outras. Essa política procurou integrar ações já em andamento 
e propondo outras, implementadas pelo PARFOR - Plano Nacional de Formação de Professores da Educação Básica (Brasil, 2009), integrado no Plano de Ações Articuladas - PAR (Brasil, 2007), proposto no bojo do Plano de Desenvolvimento da Educação - PDE (Brasil, 2007a) que pretendia integrar um conjunto de programas, para, com visão sistêmica, organizar melhor o próprio sistema educacional. Os sistemas estaduais e municipais deveriam executar ou dar suporte às atividades em parceria com as instituições de ensino superior públicas e atender aos requisitos postos para a realização das diversas atividades. Em 2017, com a mudança de governo, uma outra formulação relativa à política nacional de formação de professores foi editada pelo Ministério da Educação (Brasil, 2017) a qual não teve prosseguimento pela nova mudança de governo em 2019.

Essa política que pretendia ser articuladora acabou por se fragmentar em várias atividades paralelas postas em movimento por setores separados do Ministério da Educação, gerando algumas superposições. Há poucos dados de caráter amplo, e obtidos com metodologia multivariada agregando vários fatores, sobre o efeito desses programas e atividades diretamente na formação de professores e na educação básica. Santos, Bueno e Ferreira (2017) estudando a questão constataram a existência de maneiras diversas de cada município gerir os programas. Verificaram dificuldades na liberação dos professores para os cursos, questões de sua substituição e custos, entre outras, o que levou a que "uma parcela diminuta de profissionais inicia o programa, outra ainda menor o conclui." (op.cit., p..693). Também constatou a dificuldade dos professores em se dedicarem aos estudos pelas suas condições de trabalho. Pesou, também, a não suficiência do repasse de verbas do governo federal aos municípios. Disso resultaram a desistência e o abandono dos programas federais em favor dos programas locais, o que, segundo os autores sinaliza que a formação permaneceu importante para os municípios, com a condição de estar ajustada às condições de trabalho dos professores. Pontuam a necessidade de atenção tanto ao reconhecimento que os cursistas estão em níveis diferentes de formação profissional, quanto ao "descompasso que há entre as propostas do governo federal e as políticas municipais, a fim de que seja possível identificar o nível dos programas em relação à rede, se aquém ou além de suas experiências e expectativas.” (op.cit., p. 695). Silva (2017) analisa a partir de pesquisa as limitações do PAR no cumprimento do seu objetivo de fortalecer as relações de colaboração da União com os municípios. Depoimentos de secretários municipais de educação mostraram a carência dos recursos financeiros no PAR, as dificuldades 
administrativas que têm ante as exigências do programa e a ausência de estrutura organizacional e de pessoal que possuem. O autor aponta também que: “Os depoimentos esclarecem que as secretarias municipais de educação não foram devidamente consultadas sobre os parâmetros para a elaboração dos itens e das ações internas do PAR." Conclui que o modo como a colaboração foi estabelecida deixa o município em uma condição de submissão às normas definidas pela união "e corrobora a histórica visão restritiva do município como agente político capaz de induzir e formular políticas públicas.” (op.cit., p.342).

Quanto aos Fóruns Estaduais de Educação, propostos na perspectiva do PAR, não contaram na maioria dos estados com condições reais para sua atuação, e alguns nem chegaram a funcionar efetivamente se considerarmos suas atribuições. Também, verifica-se que em todos esses programas e ações, não aparece preocupação nenhuma com os currículos de formação ficando-se na sua implementação em geral reproduzindo o que era praticado nas rotinas institucionais. (Gatti et al., 2019).

No sentido de induzir formas diferenciadas de formação nos cursos de licenciaturas foi criado em 2007 um programa bem estruturado, de não tão grande porte, junto à Capes/MEC o Pibid (Programa Institucional de Bolsa de Iniciação à Docência), que foi mais detalhadamente regulamentado pelo Decreto 7219/2010 (Brasil, 2010). É dos poucos programas com continuidade, isso, devido à luta da comunidade educacional mobilizada em favor dela. Tem por objetivo qualificar a melhor estudantes de licenciatura para o trabalho nas escolas favorecendo, através de projetos bem dirigidos e selecionados, seu aperfeiçoamento em práticas escolares, criando maior interação universidade-escolas. Entre os programas desenvolvidos, este foi objeto de muitos estudos e, de uma avaliação abrangente. (Fetzner e Souza, 2012; Bergamachi e Almeida, 2013; Gatti, André, Gimenes, Ferragut, 2014). A avaliação relatada por Gatti e equipe (2014) contou com 21.115 depoimentos que sustentaram a importância do programa para as licenciaturas e os licenciandos destacando suas contribuições para a valorização e revitalização das licenciaturas, para a geração de questionamentos sobre o currículo dos cursos e dos estágios levando ao repensar essas atividades, propiciando maior integração entre saberes da ciência com as ciências da educação e favorecendo o contato direto dos bolsistas com a escola pública, já nos anos iniciais de seu curso, levando a uma aproximação mais consistente das teorias com as práticas. 
O Programa Residência Pedagógica, iniciativa recente do Ministério da Educação (Brasil, 2018), compõe com o Pibid um laço formativo, e, ambos favorecem a concretização da relação prática-teoria. A Residência Pedagógica é ofertada a partir da segunda metade dos cursos de licenciatura e visa a imersão do estudante na escola, propiciando intervenções pedagógicas e regência de aulas, com orientação de docentes das instituições que oferecem formação de professores e aderem ao programa. Os dois programas implementam-se a partir de bolsas e alguns outros pequenos auxílios. O Programa Residência Pedagógica, coordenado pela Capes/MEC, ainda não conta com avaliação de porte sobre suas formas de implementação nas instituições e suas contribuições. Há poucos estudos sobre esse programa, estudos mais de casos, em que alguns aspectos positivos são trazidos à luz. (Soares, 2019; Conceição, 2019; Mello et al., 2020).

Cabe aqui citar, também, três programas que, embora não sendo voltados exclusivamente às licenciaturas, e não estando dentro da política nacional de formação de professores, tiveram sobre as licenciaturas algum impacto propiciando aumento de vagas, influindo no acesso ao ensino superior, ajudando na permanência dos estudantes nos cursos e trazendo apoio financeiro por concessão de bolsas ou empréstimos, a saber: o Fies, o Prouni e o Reuni. O Fundo de Financiamento Estudantil - Fies (Brasil, 2001), também é voltado a estudantes de instituições privadas. Sofreu várias alterações em suas regulamentações, e, em 2010 foi assumido pelo Fundo Nacional de Desenvolvimento da Educação, com vários novos requisitos. Estudantes de licenciatura têm recorrido crescentemente ao programa e, a partir de 2015 foi estipulado que cursos de Licenciatura, Pedagogia e Normal Superior, da área de saúde e da engenharia deveriam ser beneficiados com 70\% das vagas de cada microrregião. Em 2018, favorecendo estudantes de Licenciatura, de medicina e cursos voltados para a formação de professores, estipulou-se que, para esses cursos, o pagamento do Fies, pode ser feito por serviços voltados às comunidades. No caso, os que fazem licenciatura devem atuar em escolas públicas. (Brasil, 2018a). O Prouni - Programa Universidade para Todos (Brasil, 2005) oferece bolsas de estudo, integrais ou parciais, para frequência a cursos de nível superior em instituições privadas pela contrapartida de isenção de tributos às instituições que a ele aderem. Embora beneficiando estudantes de licenciatura em razoável porcentagem, teve também por meta beneficiar especificamente professores das redes escolares públicas que viessem a frequentar licenciaturas. Os dados do SisProuni de janeiro 2015 mostraram que, no conjunto dos bolsistas, desde 2010, 
o percentual desses professores girou em torno de 1\%. (Brasil, 2018). Felicetti e Fossatti (2014) mostraram que a evasão do curso tem sido menor entre os bolsistas Prouni (30\%) do que entre os não bolsistas (41\%). O Reuni - Programa de Apoio a Planos de Reestruturação e Expansão das Universidades Federais, criado pelo Decreto n. 6096/2007 (Brasil, 2007b) teve por objetivo criar condições para o aumento de vagas e a permanência dos estudantes na educação superior nas instituições federais. Com suas metas quanto à ampliação de vagas teve várias frentes de apoio e financiamento: aumento dos docentes por concurso, obras de expansão de campus universitários, bolsa de assistência ao ensino, reestruturação acadêmica e inovação. Esse programa, embora atendendo a todos os tipos de graduação teve impactos consideráveis na ampliação da oferta das licenciaturas e dos cursos noturnos nas instituições federais de ensino superior.

O que se constata é que, de modo geral, há falta de monitoramento adequado das políticas educacionais implementadas. Seus impactos são pouco claros, os modelos de gestão não são avaliados para verificação de facilidades e dificuldades e para subsidiar ajustes e melhorias. O papel dos agentes não é verificado. O emprego do financiamento não é analisado devidamente, de modo geral. Há estudos esparsos, mas, ao nível do Ministério da Educação, as políticas não são desenhadas acompanhadas de um sistema consistente de monitoramento e de um plano de avaliação educacional desde seus inícios, o que garantiria constatar problemas e percalços ajudando, em processo, na melhoria de condições para suas realizações e resultantes. Monitoramento adequado contribuiria tanto para a consolidação de políticas como para suas alterações se necessário, e, mesmo para sua suspensão, se necessário, com base em constatações e dados e não em opiniões flutuantes em função deste ou daquele interesse. Faltam avaliações mais abrangentes e mais acuradas de cada um desses programas, com exceção do Pibid, especialmente abordando questões das qualidades a eles associadas, dos problemas existentes, e dos seus efeitos em relação a seus propósitos. A questão da relação público-privado também seria categoria analítica a ser considerada.

\section{Iniciativas institucionais renovadoras}

Discussões e reflexões sobre a situação da formação de professores, realizadas em algumas instituições de ensino superior, levaram a propostas que vêm mostrando inovações apreciáveis. Elas se institucionalizam renovando perspectivas e práticas e exigem esforço e alto 
grau de cooperação do coletivo docente, consciência integral da proposta relativa à formação de professores e dedicação ao projeto curricular assumido. Entre várias iniciativas vamos destacar aqui, a título de exemplo, apenas três. Elas também mostram a factibilidade de renovar quando há compromisso coletivo e vontade política. Trataremos sinteticamente da proposta das licenciaturas interdisciplinares e integradas da Universidade Federal do Sul da Bahia (UFSB), do Complexo de Formação de Professores da Universidade Federal do Rio de Janeiro (UFRJ) e da licenciatura em Educação do Campo da Universidade Federal de Santa Catarina (UFSC).

$\mathrm{Na}$ UFSB não só as licenciaturas são concebidas interdisciplinarmente, os bacharelados também, e ambos se integram na formação geral proposta. Os cursos têm o formato quadrimestral e são organizados em ciclos, em que blocos temáticos de conhecimentos são articulados na Formação Geral (FG) na qual o estudante tem contato com as culturas humanística, artística e científica, após o quê, escolhem entre as cinco grandes áreas oferecidas para realizarem o restante de seu percurso formativo. Assim, o currículo das licenciaturas não tem foco em disciplinas específicas, mas, em grandes blocos de conhecimentos que conduzem a formação, após a FG, para cinco grandes áreas: Matemática e Computação; Ciências da Natureza; Ciências Humanas e Sociais; Linguagens e Códigos e Artes. Há integração interdisciplinar entre os componentes curriculares específicos, bem como integração desses componentes específicos com os pedagógicos, e, há interface sistêmica com a educação básica, a qual é um dos pilares das atividades através da parceria, que vigora em seus diversos campi, da Universidade com a Secretaria Estadual de Educação da Bahia e Secretarias Municipais, por meio dos Complexos Integrados de Educação. Visa-se a formação de docentes para a educação básica que sejam capazes de integrar os conhecimentos de seu campo de formação com uma prática docente intercultural, que não ignorem a comunidade de origem dos alunos e ajudem no seu desenvolvimento, e que construam coerentemente sua autonomia profissional, reconhecendo a necessidade de formação constante e de renovação de suas práticas. Com isso, tem o claro objetivo de formar quadros de professores para a educação básica, com um currículo flexível, interdisciplinar e aliado a experiências concretas. As relações são baseadas no princípio da horizontalidade. Essa proposta só pode ser realizada com um novo tipo de cultura universitária e com o envolvimento dos docentes do curso com a filosofia curricular adotada, o que demanda renovação de suas práticas habituais. (UFSB, 2020; Almeida Filho et al., 2017).

O Complexo de Formação de Professores sediado na UFRJ é uma experiência compartilhada entre essa universidade, diversas outras instituições de educação superior, 
Secretarias Municipal e Estadual de Educação do Rio de Janeiro e uma rede de escolas parceiras abrangendo todos os níveis e modalidades da educação básica. O Complexo exerce um papel articulador e sua proposta é a de criar meios institucionais para que as unidades acadêmicas responsáveis pelas licenciaturas das diferentes áreas disciplinares trabalhem de forma integrada e articulada entre si, assumindo coletivamente processos de formação inicial e continuada de professores. Privilegia a ideia de estimular, nos processos formativos, práticas docentes compartilhadas, buscando-se criar ações participativas para as quais contribuem, em processo relacional horizontal, tanto os docentes, como os estudantes e gestores das instituições de nível superior envolvidas e das escolas. As ações podem ser realizadas tanto nos espaços das instituições ou das escolas como em outros espaços, como museus, centros culturais ou outros espaços públicos. A forma de funcionamento em rede é a proposta, a qual se articula em torno do Fórum Permanente de Formação de Professores, sendo que a dinamização das ações tem como importante instância os Núcleos de Planejamento Pedagógico das licenciaturas. É uma política institucional integradora que pretende criar condições para superar cercas inter e extra institucionais, que historicamente foram construídas, através de ações colaborativas, participativas e integradas. (UFRJ, 2020; 2018; 2018a; Gabriel, 2019; Gabriel e Senna, 2020).

A Licenciatura em Educação do Campo da UFSC foi proposta considerando o campo como lócus de referência essencial, com seus modos de vida e trabalho, e, foi elaborada com a participação dos que vivem nas regiões em que o curso se desenvolve. Tem como foco as Ciências da Natureza e Matemática e sua oferta é presencial. A formação nesta licenciatura considera o estudo dos elementos que compõem a memória, saberes, valores, costumes, práticas sociais e produtivas dos sujeitos do campo e da agricultura familiar. Articula conhecimentos acadêmicos com esses aspectos, e, busca fomentar a análise das características socioculturais e ambientais do território de vida dos estudantes para que eles compreendam, em sua complexidade, os conflitos e contradições existentes. Com esta articulação objetiva o desenvolvimento da capacidade teórico-prática para pensar-organizar-fazer uma escola básica do campo que estabeleça uma formação crítico-criativa, comprometida com os princípios da construção de alternativas de sustentabilidade social dos territórios rurais. Apoia-se na Pedagogia da Alternância que compreende articuladamente o Tempo Comunidade (TC) e o Tempo Universidade (TU). Com a formação no TU desenvolvem atividades nas suas comunidades, seja de diagnóstico, de aproximação com a escola, estágios em sala de aula e 
projetos comunitários de integração escola/comunidade, conforme a etapa do curso. Busca-se com esse processo educativo uno, articular a experiência de trabalho e de vida do estudante no seio da comunidade/município onde reside com a experiência de formação universitária que está realizando. Visa-se a atuação docente na Educação Básica (anos finais do Ensino Fundamental e Ensino Médio) nas comunidades rurais, em diversas áreas do conhecimento. (UFSC, 2020; Borges, et.al., 2017; Britto e Silva, 2015)

Licenciaturas em Educação do Campo existem no país desde 2006. Hoje, são mais de quarenta universidades federais de todo o Brasil que ofertam o curso e eles apresentam inovações formativas que podem inspirar outras. Mas, é preciso que haja intercâmbio maior entre os variados cursos de licenciatura com o espírito de cooperação e da necessidade de mudança de hábitos reificados.

\section{Refletindo sobre os caminhos trilhados}

$\mathrm{O}$ aspecto da descontinuidade de ações que, em geral, e com poucas exceções, afeta as políticas educacionais no país, nos diversos níveis da gestão educacional, descontinuidade que muitas vezes depende apenas do grupo gestor e suas mudanças, é aspecto a ressaltar. Algumas iniciativas tiveram certa continuidade na década presente, com reformulações ou reduções, outras não foram adiante, e outras não conseguiram firmar-se na direção de suas finalidades. A descontinuidade de políticas em educação é fato constatado, não por avaliações pertinentes, de amplo espectro, fundamentadas em análises e avaliações consistentes, mas fundamentadas em opiniões e perspectivas construídas por representações que se constroem dentro de segmentos sociais específicos. (Gatti et al., 2011; 2019) Essa cultura tem provocado rupturas em ações na área educacional não favorecendo tanto a geração de impactos mais fortes que perdurem, nem as articulações necessárias a uma boa política educacional - a que integra o diverso, trabalhando por consensos e não por imposições, e que sinaliza claramente direções, cria cooperações diversas e aproxima-se ou atinge suas finalidades. Em uma sociedade democrática a convivência e o diálogo entre perspectivas diversas, debatidas de forma aberta e solidária, constitui seu cerne, na busca de consensos na direção do bem público, que suplanta este ou aquele interesse de poder deste ou daquele grupo. Um exercício difícil que exige uma real formação democrática. Como “democracia jovem" ainda estamos nos primeiros ensaios no que respeita a essas posturas e, com muitas dificuldades face à nossa história sociocultural. 
Em que pesem boas intencionalidades e justificativas bem teorizadas para diferentes políticas encetadas nos diferentes governos, continuamos com problemas educacionais os quais são apontados por várias análises. (Soares e Delgado, 2016; Sampaio e Oliveira, 2015; Araújo, 2014). Em educação bons resultados, que é o que visam as políticas, levam muito tempo para emergir e demandam coerência e continuidade de ações por muitos anos, o que só é possível com consensos duradouros. Ainda permanece o que Tedesco (2010, p.19) apontou ao afirmar que na área da educação temos elaborado muitas soluções para problemas que não são concretos e continuamos sem soluções para os problemas concretos das redes de ensino, acrescentando que o "problema educativo é que as crianças não aprendem e que temos enormes níveis de desigualdades nos resultados de aprendizagens de nossos alunos”.

No que se refere à valorização dos professores, apesar de políticas como as do Parfor e do Fundeb, entre outras que citamos, as carreiras de docentes da Educação Básica não correspondem ao seu valor para a sociedade atual em suas complexidades, e não se mostram na maioria das regiões do país atrativas aos jovens. (Almeida et al., 2014; Castro e Carvalho, 2019). Encontra-se em exercício nas redes escolares a falta de docentes com qualificação para as áreas que lecionam, apesar do volume de matriculados nos cursos de licenciatura, especialmente nas instituições privadas (Brasil/Inep, 2019). Estudo com dados do Inep/MEC (Anuário 2019) mostra que, em 2018, apenas 48.7\% dos docentes do Ensino Fundamental e 56,3 no Ensino Médio tinham formação superior compatível com todas as disciplinas que lecionavam. Isto sinaliza que temos falta de professores em várias áreas curriculares, o que leva à existência de docentes sem formação específica a assumir essas áreas ou, simplesmente a que as disciplinas não sejam oferecidas e os alunos são promovidos sem ter sido a eles oferecidos os conhecimentos devidos. Quanto à formação inicial de docentes nas licenciaturas, apesar das tentativas havidas de reorientar e requalificar essa formação, adia-se a execução de novas propostas e, assim, a maioria dos cursos de graduação que formam professores têm currículos fragmentários, estágios precários, formação genérica com pouca identidade, parca relação com as redes escolares e seus currículos.

Há muito o que repensar e fazer em termos das políticas educacionais em geral e em relação às voltadas para a valorização e reconhecimento do trabalho dos professores na educação básica. É necessário reconhecer que houve esforços políticos em gestões educacionais na 
perspectiva de se alcançar atualização formativa dos docentes, melhoria de carreira e condições de trabalho, especialmente nas duas últimas décadas. Porém, observa-se que entre propor políticas e realiza-las tivemos descompassos, hiatos, reformulações sucessivas, que acabam por não conduzir aos efeitos qualitativos desejados expressos nas intenções dos documentos que sustentam as propostas construídas.

Com os problemas associados à gestão das políticas educacionais e sua articulação, o que se concretizou foram improvisações em relação à formação de docentes para o atendimento à expansão escolar. (Almeida e Abdalla, 2017; Gatti, 2015). A partir, mais recentemente, da constituição de um acervo de dados educacionais que tornam possível caracterizar e analisar as condições qualitativas da formação de professores e das condições da oferta educacional no Brasil, a discussão e, a construção de políticas educacionais pode ser colocada em outro patamar. É uma questão que se coloca aos pesquisadores e acima de tudo aos gestores.

\section{Referências}

Almeida filho, N.: Benincá, D; Coutinho, D. (2017). Universidade Popular e democratização de saberes: o caso da Universidade Federal do Sul da Bahia. EccoS - Revista Científica, São Paulo, n. 42, p. 39-55.

Almeida, P. C. A.; Abdalla, M. F. B. (2017). Formação inicial de docentes para os anos iniciais do ensino fundamental na perspectiva das competências para o século 21 e da educação inclusiva: informe final. Santiago do Chile: UNESCO-OREALC.

Almeida, P.A.; Tartuce, G.L.B.P.; Nunes, M.M.R. (2014). Quais as razões para a baixa atratividade da docência por alunos do Ensino Médio? Psicologia: Ensino \& Formação, v. 5, n. 2, p. $103-121$.

Anuário da Educação Brasileira - 2019. (2019). Editora Moderna, 2019.

Araújo, J.A. (2014). Educação e Desigualdade: A Conjuntura Atual do Ensino Público no Brasil. Revista Direitos Humanos e Democracia, Editora Unijuí, ano 2, n. 3, p. 125-157.

Bergamaschi, M.A.; Almeida, D.B. (2013). Memoriais Escolares e processos de iniciação à docência, Educação em Revista, Belo Horizonte, v. 29, n. 2.

Borges, M.G.; Faria, J.E.S.; Brick, E.M. (2017). Fenômenos como mediadores do processo educativo em Ciências da Natureza e Matemática na Educação do Campo. Revista Brasileira de Educação do Campo. Tocantinópolis v. 2 n. 3, p. 965-990.

Brasil. (1996). Lei no 9.394, de 20 de dezembro de 1996. Estabelece as diretrizes e bases da educação nacional. Diário Oficial da União, Brasília, DF.

Brasil. (2001). Lei n ${ }^{\circ} 10.260$, de 12 de julho de 2001. Dispõe sobre o fundo de financiamento ao estudante do ensino superior e dá outras providências. Diário Oficial da União, Brasília, DF.

Brasil. (2002). Conselho Nacional de Educação. Resolução $C N E / C P n^{\circ} 1$, de 18 de fevereiro de 2002. Institui Diretrizes Curriculares Nacionais para a formação de Professores da 
Educação Básica, em nível superior, curso de licenciatura, de graduação plena. Brasília, DF.

Brasil. (2005). Lei $n^{0} 11.096$, de 13 de janeiro de 2005. Institui o Programa Universidade para Todos - PROUNI, regula a atuação de entidades beneficentes de assistência social no ensino superior; altera a Lei no 10.891, de 9 de julho de 2004, e dá outras providências. Diário Oficial da União, Brasília, DF.

Brasil. (2006). Emenda Constitucional 53/2006 de 19 de dezembro de 2006. Dá nova redação aos arts.7, 23, 30, 206, 208, 211 e 212 da Constituição Federal e ao art. 60 do Ato das Disposições Transitórias Constitucionais. Disponível em: https://www.planalto.gov.br>emendas>emec53 Acesso em 14/12/2020.

Brasil. (2006). Ministério da Educação. Rede Nacional de Formação Continuada de Profissionais da Educação Básica. Orientações Gerais: Catálogo 2006. Brasília, DF.

Brasil. (2006a). Decreto ${ }^{0}$ 5.800, de 8 de junho de 2006. Dispõe sobre o Sistema Universidade Aberta do Brasil - UAB. Diário Oficial da União, Brasília, DF.

Brasil. (2007) Presidência da República. Decreto 6.094, de 24/4/2007: dispõe sobre a implementação do Plano de Metas Compromisso Todos pela Educação, pela União Federal, em regime de colaboração com Municípios, Distrito Federal e Estados, e a participação das famílias e da comunidade, mediante programas e ações de assistência técnica e financeira, visando a mobilização social pela melhoria da qualidade da educação básica. Brasília, DF.

Brasil. (2007a). Ministério da Educação. Inep. O Plano de desenvolvimento da educação: razões, princípios e programas. Brasília, DF.

Brasil. (2007b). Decreto $n^{\circ}$ 6096, de 24 de abril de 2007. Institui o Programa de Apoio a Planos de Reestruturação e Expansão das Universidades Federais - REUNI. Diário Oficial da União, Brasília, DF.

Brasil. (2007c). Decreto $n^{o}$ 6253/2007 de 13 de novembro de 2007 - Dispõe sobre o Fundo de Manutenção e Desenvolvimento da Educação Básica e de Valorização dos Profissionais da Educação - FUNDEB, Regulamenta a Lei no 11.494 de 20 de junho de 2007, e dá outras providências. Brasília, DF. Disponível em: http://www.planalto.gov.br/ccivil_03/_ato2007 Acesso em: 14/12/2020.

Brasil. (2008). Lei $\mathrm{n}^{\mathrm{o}} 11.738$, de 16 de julho de 2008. Estabelece Piso Salarial Profissional Nacional. Diário Oficial da União, Brasília, DF.

Brasil. (2009). Decreto $\mathrm{n}^{0}$ 6.755, de 29 de janeiro de 2009. Institui a Política Nacional de Formação de Professores do Magistério da Educação Básica e dá outras providências. Diário Oficial da União, Brasília, DF.

Brasil. (2010). Decreto n. 7.219 de 25/06/2010. Dispõe sobre o Programa Institucional de Bolsa de Iniciação a Docência e dá outras providências. Brasília, DF. Disponível em: $<$ www.capes.gov.br >. Acesso em: 04/06/2018.

Brasil. (2015). Conselho Nacional de Educação. Parecer CNE/CP n. 02/2015, aprovado em 9 de junho de 2015 - Diretrizes Curriculares Nacionais para a Formação Inicial e Continuada dos Profissionais do Magistério da Educação Básica. Brasília, DF.

Brasil. (2015a). Conselho Nacional de Educação. Resolução $C N E / C P n^{\circ}$ 2, de $1^{\circ}$ julho de 2015. Define as Diretrizes Curriculares Nacionais para a formação inicial em nível superior (cursos de licenciatura, cursos de formação pedagógica para graduados e cursos de segunda licenciatura) e para a formação continuada. Brasília, DF.

Brasil. (2017). Ministério da Educação. Política Nacional de Formação de Professores. Brasília, DF. Disponível em: <portal.mec.gov.br/ index.php?option=com 
docman \&view=download\&alias=74041-formacao-professor-final-18-10-17-pdf $>$. Acesso em: 22 nov. 2019.

Brasil. Inep. (2017). Indicadores de Fluxo Escolar da Educação Básica, Brasília, DF.

Brasil. (2018). Ministério da Educação. Coordenação de Aperfeiçoamento de Pessoal de Nível Superior - CAPES. Portaria Gab no 38 de 28 de fevereiro de 2018. Institui o Programa de Residência Pedagógica. Brasília, DF.

Brasil. (2018a). Ministério da Educação. Fies. Brasília, DF: MEC/FNDE, s.d. Disponível em: $<$ www.fnde.gov.br/financiamento/dados-estatisticos/item4753-dados-do-fies $>$. Acesso em: $12 / 12 / 2018$.

Brasil. Inep. (2019). Sinopse Estatística da Educação Superior - 2019. Brasília, DF.

Brasil. (2019). Conselho Nacional de Educação. Resolução CNE/CP 02/2019 - Diretrizes Curriculares Nacionais para a Formação Inicial de Professores para a Educação Básica e institui a Base Nacional Comum para a Formação Inicial de Professores da Educação Básica (BNC-Formação). Brasília, DF.

Britto, N.S.; Silva, T.G.R. (2015). Educação do Campo: formação em ciências da natureza e o estudo da realidade. Educação e Realidade. Porto Alegre, v. 40, n. 3, p. 763-784.

Castro, J.J.M.; Carvalho, FA.F. (2019). Configuração e atratividade da carreira docente da educação básica do município de Cametá/PA. Educação \& Formação, Fortaleza, v. 4, n.10, p. $164-179$.

Conceição, I. (2019). A residência pedagógica na formação de professores: colaborações no ensino de Geografia mediante diário de formação $.14^{\circ}$ Encontro Nacional de Prática de Ensino de Geografia: Políticas, Linguagens e Trajetórias. Universidade Estadual de Campinas, 29 de junho a 4 de julho de 2019 (Ateliê de Pesquisas e Práticas em Ensino de Geografia ISBN 978), p. $3737-3744$.

Felicetti, V. L.; Fossatti, P. (2014). Alunos Prouni e não Prouni dos cursos de licenciatura: evasão em foco. Educar em Revista, Curitiba, v. 30, n. 51, p. 265-282.

Fetzner, R.A.; Souza, M.E.V. (2012). Concepções de conhecimento escolar: potencialidades do Programa Institucional de Bolsa de Iniciação à Docência, Educação e Pesquisa, São Paulo, v. 38, n. 3.

Gabriel, C. (2019). Complexo de formação de professores: uma experiência (inter)institucional em curso. Profesorado. Revista de Currículum y Formación de Profesorado, v. 3, n. 23, p. 189-209.

Gabriel, C.T.; Senna, B. (2020). Complexo de formação de professores: espaço-tempo produtor de políticas de currículo. Série-Estudos, Campo Grande, MS, v. 25, n. 55, p. 133-153.

Gatti, B. A.; Barretto, E. S. S.; Andre, M. E. D. A. (2011). Políticas docentes no Brasil: um estado da arte. Brasília: UNESCO.

Gatti, B. A. Formar professores no Brasil: contradições, políticas e perspectivas. (2015). In: Congresso Brasileiro de Educação, 5. Bauru, Anais... UNESP, 2015. (1 CD-ROM).

Gatti, B.A.; André, M.E.D.A.; Gimenes, N.A.S.; Ferragut, L (2014). Um estudo avaliativo do Programa Institucional de Bolsa de Iniciação à Docência (Pibid). Textos FCC, São Paulo: FCC/SEP.

Gatti, B.A.; Barretto, E.S.S.; André, M.E.D.A.; Almeida, P.C.A. (2019). Professores do Brasil: novos cenários de formação. Brasília. UNESCO.

Inaf. (2015). Indicador Nacional de Alfabetismo: relatório. São Paulo: Ação Educativa, Instituto Montenegro. 
Jacomini, M. A.; Penna, M. G. O. (2016). Carreira docente e valorização do magistério: condições de trabalho e desenvolvimento profissional. Proposições, v. 27, n. 2, p. 177-202.

Leite, R. R. (2014). Remuneração e carreira docente nos municípios goianos após a implantação do Fundeb. Revista Plurais - Virtual, v. 4, n. 2, p. 20-37.

Mello, D.E.; Moraes, D.A.F.; Franco, A.A.P.; Assis, E.F.; Potoski, G. (2020). O programa residência pedagógica: experiências formativas no curso de Pedagogia. RPGERevista on line de Política e Gestão Educacional, Araraquara, v. 24, n. 2, p. 518-535. Disponível em: http://www.peiodicos.fclar.unesp.br/rpge. Acesso em: 20/01/2021.

Pretto, N. de L.; Lapa. (2010). A. Educação a distância e precarização do trabalho docente. Em Aberto, Brasília, v. 23, n. 84, p. 79-97.

Sampaio, G.T.C.: Oliveira, R.P. (2015). Dimensões da desigualdade educacional no Brasil. $R B P A E$ - v. 31, n. 3, p. $511-530$.

Santos, S. R. M.; Bueno, B. O.; Ferreira, D. (2017). O Plano de ações articuladas e as políticas de formação de professores na Baixada Fluminense: tensões e acomodações. Ensaio: Avaliação e Políticas Públicas em Educação, v. 25, n. 96, p. 675-700.

Silva, L. G. A. (2017). O Plano de Ações Articuladas e o regime de colaboração: promessas não cumpridas de fortalecimento das relações de colaboração entre os municípios e a União. RBPAE: Revista Brasileira de Política e Administração da Educação, v. 33, n. 2, p. 337-354.

Soares, M.V. (2019). Entre práticas e teorias: subprojeto letras/português sob o olhar dos residentes do Programa de Residência Pedagógica da UFPI. Educação Pública, v.19, n. 29. Disponível em:https://educacaopublica.cecierj.edu.br/artigos/19/29/entre-praticas-e-teoriassubprojeto-letrasportugues-sob-o-olhar-dos-residentes-do-programa-de-residenciapedagogica-da-ufpi Acesso em: 10/12/2020.

Soares, J. F.; Delgado, V. M. S. (2016). Medida das desigualdades de aprendizado entre estudantes de ensino fundamental. Estudos em Avaliação Educacional, São Paulo, v.27, n. 66, p. 754-780.

Tedesco, J. (2010). Presentación. In: Oliveira, D. A. et al. Políticas educativas y territórios. Modelos de articulación entre niveles de gobierno. IIPE/Unesco: Buenos Aires.

UFRJ. (2020). Universidade Federal do Rio de Janeiro. Complexo de Formação de Professores. Disponível em: https://www.formacaodeprofessores.ufej.br/?page id62 Acesso em: 12/12/2020.

UFRJ. (2018). Universidade Federal do Rio de Janeiro. O Complexo de Formação de Professores na UFRJ: um lugar compartilhado para formar professoras e professores da educação básica. [Documento Interno]. Rio de Janeiro: UFRJ.

UFRJ. (2018a). Universidade Federal do Rio de Janeiro. Complexo de Formação de Professores Docentes. Termo de Referência. Rio de Janeiro: UFRJ.

UFSB (2020). Universidade Federal do Sul da Bahia. Licenciaturas Interdisciplinares. Disponível em: https:/www.ufsb.edu.br/index.php?Itemide=282 Acesso em:27/12/2020.

UFSC (2020). Universidade Federal de Santa Catarina. Licenciatura em Educação do Campo. Disponível em: https://www.licenciatura.educampo.ufsc.br Acesso em: 30/11/2020. 